\title{
¿DE PODER NEUTRO A PODER ACTIVO? SOBRE \\ EL EFICAZ PERO INCONVENIENTE REFUERZO \\ DE LOS PODERES DE EJECUCIÓN \\ DEL TRIBUNAL CONSTITUCIONAL
}

\section{From A Neutral Power to An Active One? Analysing \\ The Effective but Inconvenient Strengthen of The Constitutional Court's Enforcement Powers}

\author{
ÁNGEL ADAY JIMÉNEZ ALEMÁN' \\ Universidad de Vigo \\ adayjimenez@uvigo.es
}

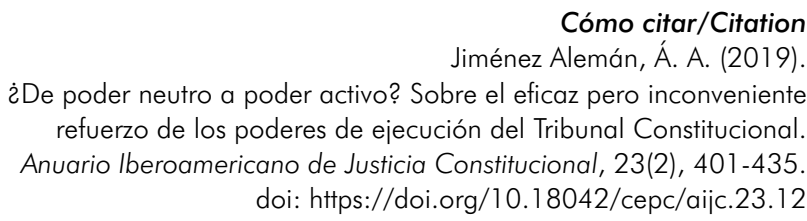

Resumen

Tras cuatro años de la ampliación de los poderes a disposición del Tribunal Constitucional para la ejecución de sus resoluciones, el debate dista de estar cerrado. La atribución de estas potestades a los tribunales constitucionales es una opción excepcional. Tanto la teoría constitucional como la experiencia constitucional comparada, particularmente la de los Estados Unidos de América, Austria y Alemania, ofrecen ejemplos de diversas formas de afrontar la resistencia por parte de autoridades públicas a la ejecución de las resoluciones de las altas instancias jurisdiccionales.

1 Este trabajo se ha realizado en el marco del proyecto "Reforma constitucional: dimensión institucional y territorial» de la Fundación Séneca - Agencia de Ciencia y Tecnología de la Región de Murcia, dirigido por Ignacio González García, ref. 20639/ $\mathrm{JLI} / 18$. 


\section{Palabras clave}

Jurisdicción constitucional; poderes de ejecución; coacción, resoluciones; derecho comparado.

\section{Abstract}

The debate about the extension of the Spanish Constitutional Court's enforcement powers is far from being concluded after four years. Granting this powers to constitutional courts in an exceptional choice. The constitutional theory, as well as the comparative constitutional experience, particularly The United States of America, Austria, Germany, offer examples of different ways to cope with public authorities' reluctance to the enforcement of the highest courts' decisions, highlighting the exceptional character of granting these powers to constitutional courts.

\section{Keywords} tive law.

Constitutional jurisdiction; enforcement powers; coercion; decisions; compara- 


\section{SUMARIO}

I. INTRODUCCIÓN. II. LA ATRIBUCIÓN DE PODERES DE EJECUCIÓN A LA JURISDICCIÓN CONSTITUCIONAL EN EL DERECHO COMPARADO: 1. Auctoritas non potestas: El Tribunal Supremo de los Estados Unidos de América. 2. Los poderes de ejecución en el modelo de Justicia constitucional europeo: 2.1. La omisión de la cuestión en la receta kelseniana. 2.2. Crisis institucionales y ejecución de resoluciones en los tribunales constitucionales alemán y austriaco. III. EL MODELO DE JUSTICIA CONSTITUCIONAL ESPAÑOL Y LOS PODERES DE EJECUCIÓN ANTES Y DESPUÉS DE LA REFORMA: 1. La LO 15/2015, de 16 de octubre, ante el Tribunal Constitucional. 2. La LO 15/2015, de 16 de octubre, ante la Comisión de Venecia. 3. La aplicación de los nuevos poderes de ejecución. IV. CONCLUSIÓN. BibLIOGRAFía.

\section{INTRODUCCIÓN}

Las reformas del Tribunal Constitucional (TC) entrañan siempre una profunda relevancia, más aún cuando le son atribuidos poderes no mencionados en el título IX de la CE, como sucedió con la Ley Orgánica 15/2015, de 16 de octubre, de reforma de la Ley Orgánica 2/1979, de 3 de octubre, del Tribunal Constitucional, para la ejecución de las resoluciones del Tribunal Constitucional como garantía del Estado de derecho. Parafraseando a Pedro de Vega (1979: 116), si la Justicia constitucional surgió como un impresionante reto histórico a una crisis generalizada del concepto de Constitución, la atribución al TC de nuevos instrumentos, o el refuerzo de los existentes, para la ejecución de sus resoluciones ha surgido como un reto en una crisis de la Constitución. En concreto, de su configuración de la organización territorial.

Es imposible obviar el contexto de esta reforma. De recordárnoslo se encarga la exposición de motivos de la ley orgánica. El objetivo de los instrumentos de ejecución con los que se dota al TC es asegurar la efectividad de sus resoluciones, adaptando la regulación de la ejecutoriedad de las resoluciones del Alto Tribunal «a las nuevas situaciones que pretenden evitar o soslayar su efectividad». El TC puede disponer ahora de instrumentos de graves consecuencias, como la posible suspensión de toda autoridad pública que desobedezca sus resoluciones (junto con el incremento en las cuantías de 
las sanciones), adoptar medidas de ejecución sin oír a las partes en el proceso por razones de urgencia y acordar la ejecución sustitutoria, tomando el TC directamente las medidas necesarias para la ejecución, pudiendo requerir la colaboración del Gobierno. Además, se prevé la condición de título ejecutivo de las resoluciones del TC y la aplicación con carácter supletorio de la Ley de la Jurisdicción Contencioso-Administrativa.

En lo que a los poderes de ejecución se refiere, el legislador orgánico se ha ido apartando progresivamente de la configuración originaria del Tribunal como institución aparentemente débil, sin cartera y sin espada y sin fuerza ni voluntad, disponiendo tan solo de discernimiento, en manos de otras autoridades para la ejecución de sus resoluciones, siguiendo la definición del poder menos peligroso de Hamilton (2004: 330-335). Esta reciente reforma ha supuesto que se llegue a plantear la posible alteración de su naturaleza de poder neutral, cuyo interés está en la integración de los poderes constitucionales a través de la generación de consenso y no en el triunfo de un poder sobre otro ${ }^{2}$.

La tramitación urgente mediante lectura única y la aprobación por una ajustada mayoría absoluta (pero que no por ello deja de serlo) no logran ocultar la agria polémica a su alrededor. Los medios de comunicación recogieron posicionamientos en contra, como los de F. Rubio Llorente ${ }^{3}$ y A. López Basaguren $^{4}$, y a favor, como los de J. de Esteban ${ }^{5}$ y E. Gimbernat ${ }^{6}$. El debate se trasladó también al propio TC a través de los recursos de inconstitucionalidad interpuestos por los Gobiernos de la Generalitat y del País Vasco, resueltos en orden inverso al que fueron registrados. En el ámbito académico se ha seguido debatiendo sobre su contenido y sus consecuencias durante estos cuatro

2 La expresión «poder neutral» la utiliza Constant en referencia al rey como gran ventaja de la monarquía constitucional, institución llamada a evitar la destrucción mutua entre los poderes constitucionales y canalizarlos hacia el movimiento general. Afirma, además, que el fallo de todas las constituciones anteriores había sido no haber creado un poder neutro (Constant, 1814: 1-5).

3 S. Gallego Díaz, CXT Contexto y Acción, «La reforma del PP aplastará al Constitucional», entrevista a F. Rubio Llorente, de 2 de septiembre de 2015. Disponible en: https://bit. ly/2OjFZVw (último acceso: 30 de octubre de 2017).

4 A. López Basaguren, «Reforma innecesaria e imprudente», El Correo Español - El Pueblo Vasco, de 5 de septiembre de 2015.

5 J. de Esteban, «Las bromas se tienen que acabar», El Mundo, de 7 de septiembre de 2015. Disponible en: https://bit.ly/2XLJ7N4 (último acceso: 2 de noviembre de 2018).

6 E. Gimbernat, "La reforma del Tribunal Constitucional», El Mundo, de 19 de septiembre de 2015. Disponible en: https://bit.ly/2DgXyz7 (último acceso: 2 de noviembre de 2018). 
años, sin que se haya alcanzado un consenso ${ }^{7}$. La cuestión llegó a regresar al Congreso de los Diputados, cuyo pleno aprobó el 20 de diciembre de 2016 la admisión a trámite de una proposición de ley orgánica de reforma de la LOTC para retornar a la regulación anterior a la última reforma presentada por el Grupo Parlamentario Vasco ${ }^{8}$.

Tanto la teoría constitucional como la experiencia constitucional comparada, particularmente la de los Estados Unidos de América, Austria, Alemania, además de nuestra historia constitucional, ofrecen ejemplos de diversas formas de afrontar la resistencia por parte de autoridades públicas a la ejecución de las resoluciones de las altas instancias jurisdiccionales, incidiendo en el carácter excepcional de la atribución de estas potestades a los tribunales constitucionales. La auténtica crisis constitucional acontecida ante la resistencia al acatamiento de las sentencias y órdenes judiciales del Tribunal Supremo de los Estados Unidos de América relativas a los casos sobre la segregación en los colegios, así como las situaciones no tan dramáticas, pero no por ello menos relevantes, en Alemania, con los casos sobre los crucifijos en los colegios públicos de Baviera, y en Austria, con respecto a la señalización bilingüe en Carintia, aportan elementos con los que analizar en la segunda parte de esta trabajo la evolución del modelo de Justicia constitucional español establecido por la Constitución de 1978 y el progresivo refuerzo y ampliación de sus poderes de ejecución.

\section{LA ATRIBUCIÓN DE PODERES DE EJECUCIÓN A LA JURISDICCIÓN CONSTITUCIONAL EN EL DERECHO COMPARADO}

Dado el carácter profundamente polémico del propio concepto de jurisdicción constitucional y sus diferentes plasmaciones prácticas, es comprensible que el debate acerca de la problemática alrededor de la ejecución de sus resoluciones sea el que menos atención ha acaparado frente a otros tópicos tradicionales, desde el primer ejercicio de autoridad jurisdiccional constitucional

7 Prueba de ello son recientes artículos de Álvarez Conde (2018) y Fernández Farreres (2018).

8 Aprobado por 176 votos a favor y 165 en contra, se encuentra en la actualidad en la Comisión Constitucional del Congreso de los Diputados. Disponible en: https://bit. ly/34kZQcn (último acceso: 23 de octubre de 2018). El 29 de abril de 2016 el Grupo Parlamentario Catalán (Democrácia i Llibertat) ya había presentado una proposición de ley de derogación de la LO 15/2015. 
consciente por parte del juez Marshall ${ }^{9}$ y la rearticulación práctica austriaca y teórica kelseniana. Es indudable que la confrontación entre una Asamblea parlamentaria responsable democráticamente y un tribunal irresponsable capaz de vetarla sigue siendo el «poderoso problema» de la jurisdicción constitucional (Cappelletti, 1979). Este poderoso problema viene acompañando a la institución en su, hasta ahora, irrefrenable expansión hasta alcanzar una presencia casi global ${ }^{10}$, en su avance hasta erigirse como un elemento característico del constitucionalismo de la segunda mitad del siglo $\mathrm{xx}$, hasta ser considerada como el mejor antídoto contra el autoritarismo (Issacharoff, 2015). Y, a su vez, no deja de ser la cuestión latente que determina toda polémica alrededor de la jurisdicción constitucional, incluida la que nos ocupa, la resistencia a dar debido cumplimiento a sus resoluciones por parte de autoridades públicas.

Es sorprendente la capacidad de los tribunales constitucionales para influir y determinar el desarrollo de los sistemas políticos en los que se en-

9 No quiero obviar (aunque me limite a mencionar muy someramente) los precedentes de esta institución en la tradición jurídica anglosajona, precedentes que no resultan ni tan remotos ni tan extraños, a pesar de que reconozcamos que no se trata de idénticos instrumentos jurídicos. Así, el primer elemento que hemos de tener en cuenta es el estudiadísimo caso Bonham en 1610, que permitió al juez Coke afirmar: «It appears in our books, that in many cases, the common law will control Acts of Parliament, and sometimes adjudge them to be utterly void». Para el análisis de este caso y el debate doctrinal que ha generado es más que conveniente acudir al estudio de Fernández Segado (2013), junto con los artículos seminales de los máximos representantes originarios de las dos posturas enfrentadas, Plucknett (1926-1927) y Thorne (1938). Esta facultad sí que fue ejercida por los tribunales de los dominios del Imperio británico que contaban con «constituciones» aprobadas por la Corona o el Parlamento británico (vid. Chen y Poiares, 2013). Estos tribunales podían declarar nula cualquier disposición normativa de la Asamblea legislativa de su dominio que consideraran contraria a la "constitución» colonial. Lo cierto es que la idea de la jurisdicción constitucional, en el sentido de capacidad de los órganos jurisdiccionales para el control del proceso de creación normativa tomando como parámetro a una norma, la constitución, a la que se le reconoce supremacía y pleno valor jurídico, llevaba tiempo deambulando en el discurso jurídico anglosajón, como un mármol que esperaba al escultor que le diese forma definitiva. Tal es así, que García de Enterría (1981) identificó estas dos técnicas, la supremacía constitucional y la judicial review, como específicas del common law.

10 Según los cálculos realizados por T. Ginsburg, y M. Versteeg (2013), 151 países de 204 entre 1781 y 2011 han adoptado alguna forma de control jurisdiccional de constitucionalidad. La tendencia se agudizó a partir de 1950, período en el que se alcanza una cifra cercana al $80 \%$. 
cuentran, a pesar de disponer habitualmente de escasos recursos, cuando no carecen de capacidad para la ejecución directa de sus resoluciones. Las decisiones de estos órganos implican coacción a autoridades que a su vez son capaces de minar la acción de los órganos jurisdiccionales constitucionales. Por lo que su autoridad descansa en que sean un factor de equilibrio en el enfrentamiento entre actores políticos y que así sean apreciados por estos ${ }^{11}$. En los estudios dedicados al análisis sobre los elementos o factores que permiten valorar el poder de estos tribunales, la atribución de jurisdicción sobre la ejecución de sus sentencias brilla por su ausencia ${ }^{12}$. La literatura insiste en identificar la autonomía y la autoridad como las dimensiones a tener en cuenta al evaluar el funcionamiento de los altos órganos jurisdiccionales. Pero a la hora de construir fórmulas que permitan medir la autoridad de los tribunales constitucionales, la ejecución de sus resoluciones es un factor del que se prescinde ${ }^{13}$. Parafraseando la definición intuitiva de poder clásica enunciada por Robert Dahl hace sesenta años (1957: 201), los tribunales que ejercen jurisdicción

11 G. Vanberg (2015) ha revisado la extensa bibliografía publicada sobre esta cuestión durante los últimos veinte años, concluyendo que la autoridad de los órganos jurisdiccionales deriva de una combinación de razones endógenas, como el propio interés de las autoridades en una jurisdicción influyente de la que obtienen beneficios, y exógenas, como el apoyo ciudadano a la independencia judicial. Este mismo autor también ha destacado la relevancia de la transparencia y la visibilidad del funcionamiento de los tribunales constitucionales a la hora de alcanzar el acatamiento voluntario de sus decisiones (G. Vanberg, 2001).

12 Por ejemplo, Gardbaum (2018) analizó los criterios que la literatura utiliza comúnmente para evaluar el poder de un tribunal constitucional. El autor descarta como criterios la influencia internacional del tribunal a través de la exportación de su doctrina, o que el tribunal haya sido dotado con una forma de judicial review más o menos fuerte. El elemento clave sería la capacidad del Tribunal para determinar la resolución de cuestiones constitucionales y políticas relevantes, su impacto real a la hora de generar resultados sociales y políticos.

13 En este mismo sentido, Brinks y Blass (2017) construyen y aplican un modelo multidimensional para medir el poder jurisdiccional. Una de las dimensiones tenidas en cuenta es la autoridad de los tribunales, la cual es definida por los autores como la capacidad efectiva de los tribunales para intervenir en un amplio abanico de conflictos políticos a solicitud de un número amplio de actores. La capacidad de decisión es tenida en cuenta, en el sentido de cuál es el ámbito de los efectos de las resoluciones de los tribunales constitucionales (generales o solo para las partes enfrentadas en el proceso constitucional; o si la declaración de inconstitucionalidad tiene efectos erga omnes o supone la no aplicación de la disposición legal al conflicto en concreto). Si los tribunales cuentan o no con capacidad para ejecutar sus resoluciones es un factor ignorado por el estudio. 
constitucional han logrado que el resto de actores de sus respectivos sistemas constitucionales hagan lo que no hubiesen hecho de otra manera. Y ello, a pesar de la carencia generalizada, o la falta de concreción, de instrumentos de coacción directa que garanticen la aplicación de sus resoluciones.

\section{AUCTORITAS NON POTESTAS: EL TRIBUNAL SUPREMO DE LOS ESTADOS UNIDOS DE AMÉRICA}

El ejemplo por antonomasia de este fenómeno es el Tribunal Supremo de los Estados Unidos. Gracias a su facultad para interpretar la Constitución, esta institución ha adquirido una posición central en el sistema político estadounidense. Esta evolución es difícil de deducir de la literalidad del parco art. III de la Constitución estadounidense, que, como es bien sabido, ni siquiera menciona la función que le ha granjeado su poder y reconocimiento, la judicial review. Como observó Tocqueville (2010: 253-262), aquí radicaba la principal distinción entre el juez americano del juez europeo. Y a pesar del afán y rotundidad con los que se declaró la inexistencia de cuestionamiento en los Estados Unidos de esta potestad, aún hoy se sigue reiterando el debate sobre la propia constitucionalidad de esta función ${ }^{14}$. Su historia no ha estado libre de resistencias a la ejecución de sus sentencias, como puede observarse en las estudiadísimas resoluciones que componen The School Segregation Cases. Caso que también «muestra el vínculo, a menudo necesario, entre el cumplimiento y ejecución efectivos de una sentencia y la colaboración del poder ejecutivo» (Breyer, 2017: 99).

La sentencia en Brown v. Board of Education of Topeka, 347 U.S. 483 (1954), inauguró una importantísima serie de resoluciones fundamentales para la evolución constitucional estadounidense y el avance de los derechos civiles, derogando la doctrina «iguales pero separados» que había llegado al Tribunal medio siglo antes en relación con la regulación del transporte (Plessy v. Ferguson, 163, U.S. 537 [1896]). El mérito se suele atribuir a partes iguales tanto al presidente del Tribunal de ese momento, Earl Warren, quien logró una sentencia unánime, como al activismo para acabar con la segregación en todas sus manifestaciones realizado por Thurgood Marshall durante décadas, quien acabaría siendo el primer juez negro del Tribunal Supremo. Todo empezó por el rechazo por parte de las autoridades locales de la demanda de cinco niños negros solicitando ser admitidos en colegios para blancos. La decisión

14 Hace más de un siglo que C. A. Beard (1912) analizó los diferentes argumentos sobre esta cuestión, que dista de estar cerrada, con autorizadas voces que hoy abogan por su abolición (Tushnet, 1999; 2011). 
se basó en que las instalaciones educativas segregadas por motivo de raza son inherentemente desiguales y, por lo tanto, contrarias a la decimocuarta enmienda de la Constitución:

We conclude that, in the field of public education, the doctrine of "separate but equal" has no place. Separate educational facilities are inherently unequal. Therefore, we hold that the plaintiffs and others similarly situated for whom the actions have been brought are, by reason of the segregation complained of, deprived of the equal protection of the laws guaranteed by the Fourteenth Amendment ${ }^{15}$.

A pesar de las afirmaciones sobre una posible igualación entre las escuelas de las poblaciones negra y blanca con respecto a los recursos y los programas de estudio, el Tribunal sostuvo que la relevancia de la educación como cimiento de la ciudanía y de una sociedad democrática, junto con la constatada reducción de oportunidades educativas para la población negra ocasionadas por la mera segregación racial, hacen que la segregación en todo caso sea inconstitucional (Feinman, 2012: 100-103).

Esta decisión y las órdenes de acatamiento del Tribunal fueron masivamente desobedecidas en los estados del sur, lo que obligó al Tribunal Supremo a dictar una nueva sentencia, Cooper v. Aaron, 358 U.S. 1 (1958), demandando obediencia a su resolución. Una de las figuras líderes de la resistencia fue el gobernador de Arkansas, Orval Faubus, quien ordenó el despliegue de la Guardia Nacional al prohibir el acceso de los estudiantes negros a los colegios de Little Rock. Como respuesta, el presidente Eisenhower decretó el envío del Ejército federal con la misión de proteger a los estudiantes y el orden público. Ante esa agitación social e institucional, la dirección de uno de los colegios solicitó con éxito al Tribunal del Distrito que pospusiera la entrada en vigor de la orden del Tribunal Federal. Sin embargo, este último tribunal anuló la resolución del tribunal inferior, afirmando que los derechos constitucionales de los demandantes no podían ser sacrificados frente a la violencia y el desorden a raíz de las conductas del gobernador y de la Asamblea legislativa de Arkansas:

No state legislator or executive or judicial officer can war against the Constitution without violating his undertaking to support it. [...] The basic decision in Brown was unanimously reached by this Court only after the case had been briefed and twice argued and the issues had been given the most serious consideration. [...] The principles announced in that decision and the obedience of the States to them, according to the command of the Constitution, [358 U.S. 1, 20] are indispensable

15 Disponible en: https://bit.ly/2L7felp (último acceso: 25 de junio de 2019). 
for the protection of the freedoms guaranteed by our fundamental charter for all of us. Our constitutional ideal of equal justice under law is thus made a living truth ${ }^{16}$.

Como ilustró Alexander M. Bickel (1962: 244-272), en cualquier crisis de ejecución de sus resoluciones, el Tribunal Supremo estadounidense depende totalmente de la colaboración del Ejecutivo. Y por mucho que esta colaboración esté legalmente establecida y en la práctica se preste, nada garantiza la plena implicación de estas autoridades en la ejecución de las resoluciones judiciales. La principal labor del Tribunal es alcanzar consensos, y este es el principal mecanismo del que dispone para el cumplimiento de sus resoluciones. A pesar de lo dramático de la situación y la gravedad de la crisis constitucional, no se otorgaron poderes directos al Tribunal Supremo estadounidense para la ejecución directa de sus resoluciones. En la actualidad, se sigue confiando en el art. VI de la Constitución, que declara a la Constitución como la ley suprema, y en el juramento de todas las autoridades públicas a acatarla previsto también en ese artículo. Sin olvidar la afirmación de Marshall en Marbury $v$. Madison sobre la jurisdicción exclusiva de los tribunales a la hora de determinar qué es lo que dice la ley, de forma vinculante para todas las autoridades, ya sean federales o estatales.

De hecho, la doctrina más reciente sigue insistiendo en las lagunas acerca de lo que sucede una vez el Tribunal Supremo de los EE. UU. emite su resolución (Baum, 2016: 191-209). Los mecanismos utilizados para corregir el incumplimiento de las resoluciones del Tribunal son indirectos. En caso de un incumplimiento voluntario de una resolución del Tribunal por parte de una autoridad pública, quienes tengan legitimidad activa pueden acudir a los tribunales inferiores para demandar la ejecución de la resolución. Serán los tribunales inferiores los que ordenen el cumplimiento de la resolución del Tribunal Supremo y, eventualmente, este en última instancia. En circunstancias normales el sistema de ejecución de resoluciones se basa en el cumplimiento previo. Las autoridades temen los costes de todo tipo (tanto económicos como en términos de prestigio) que supone un proceso judicial y el riesgo de que el Tribunal acabe condenando su conducta. Ahora bien, en ciertas ocasiones las autoridades prefieren asumir el riesgo, especialmente cuando consideran que su posición está respaldada por su electorado, como muestra el caso sobre la segregación en los colegios. Siendo consciente de sus limitadísimas capacidades ejecutivas, el Tribunal recurre a otros mecanismos, a su vez, igualmente indirectos, como la claridad a la hora de formular sus resoluciones, o la generación de un clima favorable entre las autoridades ejecutivas y judiciales que

16 Disponible en: https://bit.ly/37ElI4z (último acceso: 25 de junio de 2019). 
facilite el acatamiento pacífico. Esta patente falta de capacidad ejecutiva del Tribunal no ha supuesto la disminución de su potencial como instrumento para la transformación social ${ }^{17}$. Esta realidad contrasta por la opción articulada por los tribunales arquetipos del modelo concentrado, los tribunales constitucionales austriaco y federal alemán. Aunque, por mucho que se hayan constituido como auténticas referencias a la hora de diseñar institucionalmente otros tribunales constitucionales (especialmente el Tribunal Constitucional Federal alemán), la soluciones por las que optaron en cuanto a la ejecución de sus sentencias no han sido secundadas de forma extensa, como veremos a continuación.

\section{LOS PODERES DE EJECUCIÓN EN EL MODELO DE JUSTICIA CONSTITUCIONAL EUROPEO}

\subsection{La omisión de la cuestión en la receta kelseniana}

Los poderes de ejecución tampoco recibieron mayor atención en la reformulación práctica austriaca y teórica kelseniana ${ }^{18}$, a pesar de que se encuentren entre las diferencias de las jurisdicciones constitucionales estadounidense y europea, junto con los debates entre los modelos difuso y concentrado ${ }^{19}$, el control de constitucionalidad concreto y abstracto, y, acechando también tras ellos, las diferencias entre las tradiciones judiciales del common law y del civil law (Rosenfeld, 2004: 635-638).

17 Hall (2011: 160-165) analiza las circunstancias en las que el Tribunal consigue un acatamiento generalizado de sus resoluciones, a pesar de que sean contrarias a los intereses de los actores políticos. Las resoluciones del Tribunal cuentan con más posibilidades de acatamiento pacífico por parte de las autoridades públicas si son apoyadas por la opinión pública. Una de las conclusiones del autor es que la carencia de poderes económicos o policiales del Tribunal no ha sido obstáculo para obtener el acatamiento generalizado de sus decisiones, además de su posicionamiento como actor influyente en el sistema constitucional estadounidense.

$18 \mathrm{Y}$, de hecho, sigue sin recibirla. En un trabajo de derecho constitucional comparado dedicado a la Justicia constitucional en Europa no se recoge entre las cuestiones abordadas (De Visser, 2015), como tampoco se hace en el clásico de Favoreu (1995). Y en otro trabajo de ámbito universal de Harding y Leyland (2009), apenas es objeto de comentario en un párrafo en la introducción y una reducida reseña en los capítulos dedicados al estudio de los tribunales constitucionales de Austria, Rusia e Indonesia.

19 Cuestión clásica en la estructura del control de constitucionalidad la denomina Tushnet (2014: 49-56). 
La Constitución austriaca de 1920, ahora en forma de Tribunal Constitucional y de modelo concentrado, fundamentada profusamente por Kelsen ${ }^{20}$, es la que va a dejar de ser excepción para convertirse en norma. Tal es así que los modelos de soberanía parlamentaria son hoy los que resultan exóticos frente a los de soberanía constitucional (Ginsburg, 2008). Partiendo del reconocimiento del valor normativo de la constitución como axioma, Kelsen (2011) advirtió sobre la adopción de un control de constitucionalidad como corolario necesario para que la constitución vaya más allá de «un deseo sin fuerza obligatoria». El argumento que afirma que la constitucionalidad, tanto formal como material, de la producción y aplicación normativa, o «regularidad» en los términos de Kelsen ${ }^{21}$, no encuentra mejor descanso que en la institución de un tribunal independiente (tanto por la inamovilidad de sus miembros como por su única sujeción a la constitución y a su ley), compuesto por un número moderado de juristas propuestos a través de la combinación de los órganos estatales a los que está llamado a controlar, como garantía preventiva y represiva frente a actos irregulares que puede anular, y por motivo de esta capacidad ha de ser instancia central y suprema, fue ganando adeptos ${ }^{22}$.

Si bien el razonamiento lógico sigue siendo irrebatible (la Constitución necesita ser sancionada jurisdiccionalmente para poseer pleno valor norma-

20 Sigo la aclaración de García Balaunde (2009) acerca de la paternidad del modelo concentrado de jurisdicción constitucional, quien lo considera una obra colectiva fruto de los proyectos liderados por el canciller Stern durante la redacción de la Constitución de 1920.

21 «La garantía jurisdiccional de la Constitución — la justicia constitucional— es un elemento del sistema de los medios técnicos que tienen como fin el asegurar el ejercicio regular de las funciones estatales» (Ibid.: 254).

22 Por lo tanto, la "garantía» de la Constitución ha de estar depositada en un órgano que no sea el legislador, en un órgano constituido para tal fin o en la jurisdicción ordinaria, decantándose Kelsen, como bien sabemos, por la primera opción (1995: 186). A la experiencia estadounidense achacaría ser «a great danger to the authority of the constitution» (1942), ya que implicaba la ausencia de un único criterio ante la posibilidad de que múltiples órganos jurisdiccionales realizaran un control incidental de constitucionalidad con resultados contradictorios, problema que no se terminaba de salvar mediante el recurso al Tribunal Supremo y la doctrina del stare decisis. A su vez, la configuración americana delega el interés por la constitucionalidad de la legislación en manos privadas, al no existir ningún mecanismo que permita a un órgano estatal iniciar un control de constitucionalidad. En el mismo texto, Kelsen propone como instrumento de garantía especialmente efectivo la responsabilidad penal de los titulares de los órganos que hayan participado en la realización de la ley inconstitucional, mecanismo que no ha encontrado atención doctrinal y práctica. 
tivo), y los defectos del principal mecanismo de control de constitucionalidad habían quedado patentes en la contrastada experiencia estadounidense, lo cierto es que, frente a este diagnóstico, la receta kelseniana no va más allá de la prescripción de un control de constitucionalidad directo y concentrado en un único órgano jurisdiccional. La concreta articulación de este órgano queda en manos de los constituyentes, ya que «no se puede proponer una solución uniforme para todas las constituciones posibles. La organización de la jurisdicción constitucional deberá modelarse sobre las particularidades de cada una de ellas» (Kelsen, 2011: 276). Una de esas particularidades ha sido la ejecución de las resoluciones, omitida por Kelsen, a pesar de que no deja de ser uno de los posibles problemas de la «regularidad» de la producción y aplicación normativas, y que ha sido una parte más de los múltiples ejercicios de prueba y error de ingeniería institucional que se han realizado siguiendo sus instrucciones en mayor o menor medida. Todas estas variables van a determinar la actuación, la legitimación y el éxito de la jurisdicción constitucional, siempre enfrentada a lo político como límite, pero también como elemento esencial de su función. Comprensible que Eisenmann, discípulo directo de Kelsen, resumiera la función del primer Tribunal Constitucional austriaco como «haute et difficile misión d'arbitrage politique» (1986: 289).

\subsection{Crisis institucionales y ejecución de resoluciones en los tribunales constitucionales alemán y austriaco}

A pesar de que estos tribunales han contado tradicionalmente con instrumentos para la ejecución de sus resoluciones, como puede constatarse en el estudio elaborado por Arzoz (2016), también han tenido que enfrentarse a la resistencia de autoridades públicas.

A grandes rasgos, en ambos casos los tribunales constitucionales protagonizan los procesos de ejecución, sin que se admita la ejecución a instancia de parte. Si bien, en el caso del decano de los tribunales constitucionales y de acuerdo con la Constitución austriaca de 1920, la ejecución de las sentencias es competencia del presidente federal, aunque la Ley del Tribunal Constitucional de 1921 apartó de su ejecución las sentencias sobre demandas patrimoniales y se la atribuyó a los tribunales ordinarios, regulación que fue elevada a la Constitución en 1925. Así sigue estando previsto en la actualidad en el art. 146 de la Constitución, sobre el que hay que destacar que la solicitud corresponde al Tribunal Constitucional, que la trasladará al presidente federal como responsable de la ejecución de las sentencias, pudiendo este acudir a cualquier órgano federal o estatal, e incluso al Ejército como recurso de última instancia.

A diferencia del modelo austriaco, la regulación de los poderes de ejecución del Tribunal Constitucional Federal alemán no ha sido elevada a su Ley 
Fundamental, sino que se encuentra en su ley reguladora. Un parco art. 35 atribuye al Tribunal capacidad para identificar al órgano responsable de la ejecución de su decisión y la forma en la que ha de hacerlo (algo bastante común en los tribunales constitucionales europeos, como se comentará más adelante). Ha sido el propio Tribunal el que ha desarrollado esta potestad como parte de su autonomía procesal delegada por el legislador (Rodríguez-Patrón, 2001: 147), autodenominándose pronto «señor de la ejecución» (Arzoz, 2016: 24). Junto con el art. 35 de la ley del Tribunal Constitucional Federal, hemos de tener en cuenta también el art. 31, que otorga carácter automáticamente imperativo a las resoluciones del Tribunal, y especifica que serán vinculantes para todos los órganos federales o de los Länder, así como para todas las autoridades y tribunales. Las decisiones sobre la constitucionalidad de las leyes tienen fuerza de ley y su carácter es semejante al de las leyes parlamentarias. En muy raras ocasiones ha empleado el Tribunal Constitucional Federal la potestad para emitir órdenes ejecutivas aplicando el art. 31 de su ley. Ha sido más habitual que recurra a ellas para imponer soluciones legislativas de carácter temporal (Gawron y Rogowski, 2016: 211). En ambos casos, la destitución de autoridades públicas queda bajo un procedimiento específico propio de la jurisdicción constitucional, pero que no está vinculado a la ejecución de sentencias.

Los tribunales constitucionales austriaco y alemán han encontrado oposición, si bien muy excepcional, en esta difícil misión de arbitraje y de generación de consenso. En concreto, el primero, en Carintia, en el caso de la señalización bilingüe en los municipios con presencia superior al $10 \%$ de la minoría eslovena. Y el Tribunal Constitucional Federal alemán en Baviera, tras la sentencia que ordenó retirar los crucifijos de las aulas de las escuelas públicas de primaria.

En este último caso, la oposición y resistencia a acatar la Sentencia BVerfGE 93,1 de 16 de mayo de 1995, supuso la mayor crisis que había sufrido el Tribunal Constitucional Federal alemán hasta ese momento, llegándose a cuestionar hasta su pervivencia. Baviera y Sarre son los dos únicos estados alemanes de mayoría católica. La presencia del crucifijo en las aulas de los colegios públicos de primaria del estado de Baviera era obligatoria desde 1983. A pesar de la aprobación con el voto favorable de una amplia mayoría en la Asamblea legislativa del Land de Baviera, de contar también con un extenso respaldo de la opinión pública y de apenas suponer la positivización de una práctica consuetudinaria solo interrumpida durante el régimen nazi, el reglamento escolar para las escuelas públicas de Baviera acabó siendo declarado inconstitucional por una sala fuertemente escindida. La inconstitucionalidad se fundó en la libertad religiosa y de conciencia (art. 4 Ley Fundamental alemana) y el «derecho natural» de los padres a educar a sus hijos (art. 6). La 
sentencia afirma que «la cruz es símbolo de una creencia religiosa determinada, y no mera expresión de la cultura occidental, forjada bajo influencia del cristianismo». Y, a su vez, que "la colocación de cruces tampoco se justifica con base en la libertad religiosa, entendida en sentido positivo, de los padres y estudiantes de confesión cristiana. La libertad de credo positiva la tienen todos los padres y estudiantes de confesión cristiana» (Schabe, 2009: 178). Tres magistrados expresaron su distanciamiento. Las declaraciones en contra de la sentencia se fueron sucediendo, algunas de ellas llamando a la resistencia abierta, como la del antiguo consejero de cultura del Land de Baviera Maier, quien comparó la sentencia con la retirada de las escuelas de los crucifijos por los nazis. Kohl, canciller federal en ese momento, y Ratzinger, quien sería Papa más tarde, también expresaron su opinión en contra de la decisión del Tribunal. Unos 30000 ciudadanos se congregaron en una manifestación en Múnich liderados por autoridades políticas y la resistencia a la aplicación de la sentencia en los colegios fue generalizada (solo dos la acataron). Finalmente, la Asamblea legislativa de Baviera aprobó una nueva norma que permitía a los directores de los colegios realizar los ajustes necesarios en caso de conflicto por la presencia del crucifijo en las aulas, bajo el principio general de que su presencia era obligatoria (Collings, 2015).

En Austria también se asistió a la contumaz renuencia del fallecido líder de ultraderecha Haider cuando ocupaba el cargo de gobernador del Land de Carintia a acatar las sentencias del Tribunal Constitucional austriaco. El Tribunal demandó la doble señalización en alemán y esloveno en varios municipios donde la población eslovena, aunque de presencia minoritaria, era superior al $10 \%$ del total de esa región. El enfrentamiento se prolongó durante años, mientras se sucedían hasta nueve sentencias (Schabe, 2009: 182).

Por mucho que la ejecución de las resoluciones sea una función inherente al ejercicio de la jurisdicción, y a pesar de que dos paradigmas de tribunal constitucional como el austriaco y el alemán puedan desarrollarla (no así el italiano [Zagrebelsky y Marcenò, 2012]), no se ha atribuido de forma general ni se suele enumerar entre las funciones de la jurisdicción constitucional, ya sean funciones propias o accesorias. Así, el control de constitucionalidad concreto y/o abstracto, la protección de derechos fundamentales (Stone Sweet, 2012: 892-895) y la resolución de conflictos entre órganos estatales, constituyen el conjunto de competencias comúnmente atribuidas y que la doctrina suele considerar como propias ${ }^{23}$. Otras funciones, como la jurisdicción

23 «Consideramos que son tres las funciones que especifican a la jurisdicción constitucional: 1) una función jurisdiccional propia: pronunciarse sobre el reparto de competencias previsto por la Constitución, y, en especial, sobre el reparto de 
electoral, sobre partidos políticos, o sobre autoridades políticas, se consideran como auxiliares o secundarias. Ningún tribunal constitucional ejerce todas las funciones, pero ninguno propiamente denominado como tal carece del control de constitucionalidad (Harding y Leyland, 2009: 7).

Como ha afirmado Xabier Arzoz (2016), «una jurisdicción constitucional, por el mero hecho de serlo, no tiene por qué ser al mismo tiempo titular de poderes de ejecución: la Corte Costituzionale no fue dotada de poderes de ejecución». Al ejemplo del Alto Tribunal italiano no solo se puede incorporar el Tribunal Supremo estadounidense, sino la mayoría de los tribunales constitucionales y supremos que ejercen la jurisdicción constitucional pertenecientes a la Comisión de Venecia del Consejo de Europa. De los informes enviados por treinta y nueve países al XV Congreso de la Conferencia Europea de Tribunales Constitucionales celebrado en Bucarest en mayo de $2011^{24}$, se extrae que treinta y seis tribunales constitucionales carecen de esta capaci$\mathrm{dad}^{25}$, contando con ella Alemania, Albania, Austria y España. Por lo tanto,

competencias en la Constitución y la ley; 2) una función política propia: establecer unos límites a la acción de los poderes públicos y acotar así la influencia de cada uno de ellos en el Estado; regular la distribución de poder; y 3) una función normativa propia: una participación específica por vía jurisprudencial en la producción de la ley y del Derecho constitucional» (Acosta Sánchez, 1998: 343).

24 Dedicado a la "Justicia Constitucional: Funciones y relaciones con otras autoridades públicas». Una de las preguntas recogidas en el cuestionario confeccionado por la organización inquiere expresamente si el Tribunal Constitucional tiene la capacidad de exigir la ejecución de sus resoluciones a otros órganos públicos. Se puede acceder a ellos en https://bit.ly/2OG3C9K (último acceso: 2 de noviembre de 2018).

25 En concreto, dentro de esa carencia de titularidad de poderes de ejecución, es oportuno mencionar ciertas particularidades que van desde el Tribunal Federal suizo, que está completamente apartado de la ejecución de sus resoluciones en aplicación del principio de separación de poderes, a casos cuyas normativas no prevén nada al respecto y desconocen alguna situación de esta índole, como los tribunales constitucionales o supremos de Andorra, Armenia, Azerbaiyán, Bielorrusia, Bélgica, Bosnia y Herzegovina, Bulgaria, Chipre, Dinamarca, Eslovaquia, Georgia, Hungría, Irlanda, Italia, Letonia, Lituania (apenas menciona retrasos en el cumplimientos), Luxemburgo, Mónaco, Montenegro, Rusia Polonia, Portugal y Rumanía. Además, se dan regulaciones como la del Tribunal Constitucional de Macedonia, que no dispone de medios de ejecución directa, pero sí puede supervisar la ejecución (en concreto esta función le corresponde a su secretario general) y dirigirse al Gobierno para que garantice su ejecución, o la de Ucrania, que puede solicitar a los órganos estatales una confirmación de la ejecución. O la de los altos tribunales de Malta y Noruega, donde le corresponde a la parte dirigirse a las autoridades. Es muy común que el tribunal pueda estipular cuál el órgano responsable del cumplimiento de la resolución 
los poderes de ejecución constituirían una función que, por natural que pueda ser a la jurisdicción, resultaría eminentemente accesoria para la Justicia constitucional, donde su titularidad no es imperativa.

\section{EL MODELO DE JUSTICIA CONSTITUCIONAL ESPAÑOL Y LOS PODERES DE EJECUCIÓN ANTES Y DESPUÉS DE LA REFORMA}

Nuestro modelo de Justicia constitucional es impuro en atención a la diversidad de competencias atribuidas al Tribunal (Ferreres, 2009: 29-32). Y en cuanto a lo amplio de su jurisdicción, tiene bastante poco que envidiar a otros tribunales más allá del alemán (Rubio Llorente, 1992), siendo este su referente ${ }^{26}$. También en los poderes de ejecución es apreciable la fuerte influencia de este modelo en el origen de nuestro TC, que, a diferencia de otras realizaciones concretas de la Justicia constitucional, como las de los Estados Unidos y la de la casi totalidad de los miembros de la Comisión de Venecia del Consejo de Europa, como acabamos de ver, viene contando con potestades para ejecutar sus resoluciones desde el Proyecto de Ley de la LOTC, progresivamente reforzadas ${ }^{27}$. Tanto es así que no cabe duda de la proyección de la redacción del art. 35 de la Ley reguladora del Tribunal Constitucional alemán sobre el originario art. 92 de la LOTC.

Es comprensible que se acudiese al derecho comparado para encontrar soluciones de efectividad contrastada que permitiesen superar la amarga experiencia del Tribunal de Garantías Constitucionales durante la II República. Este Tribunal sufrió una crisis para la ejecución de su primera sentencia. La respuesta de la Generalitat de Cataluña a la declaración de inconstitucionalidad, por falta de competencia legislativa, del Proyecto de Ley de Contratos

y la forma, o que esta función le corresponde al Gobierno de la nación (Serbia), que puede haber establecido sanciones de naturaleza pecuniaria para las autoridades renuentes al cumplimiento (Moldavia). Finalmente, el Alto Tribunal turco preveía que se le otorgara en un corto plazo de tiempo capacidad de relación circunscrita a la aprobación de una nueva acción semejante al recurso de amparo.

26 «El modelo que nuestros constituyentes adoptan, aquí como en tantos otros lugares del texto superior, es el modelo alemán. Lo adoptan, pero a la vez introducen alguna variante importante» (García de Enterría, 1981: 38).

27 A la redacción originaria de los arts. 92 y 97 LOTC se hicieron dos enmiendas a iniciativa de Coalición Democrática y del Grupo Socialista, incorporándose el carácter preferente y urgente del auxilio judicial. Pasaron a ser finalmente los arts. 87 y 92, respectivamente, aprobados sin discusión en los plenos del Congreso de los Diputados y del Senado. Vid. Cortes Generales (1980). 
de Cultivos aprobado por el Parlamento catalán el 21 de marzo de 1934, fue no acatar la sentencia y aprobar esta ley en el mismo día que se publicó la sentencia. Ante la gravedad de la situación llegó a intervenir el presidente del Consejo de ministros, Samper, a pesar de considerar que la ejecución de la sentencia no podía corresponder propiamente al Gobierno, al haber sido parte en el proceso constitucional (Bassols Coma, 2010: 93-103). Esta crisis marcó el devenir de la institución. Un año más tarde aún se recogen intervenciones en las que se discute sobre el trámite de ejecución, como la del vocal Beceña, abogando para que este sea una potestad discrecional del Gobierno (Urosa Sánchez et al., 1999: 359).

Este episodio no fue óbice para que se generase un consenso unánime alrededor de la conveniencia de recuperar la Justicia constitucional en el proceso constituyente de 1978. Pero no por ello dejó la doctrina de alegrarse de que se hubiesen corregido dos defectos con respecto al Tribunal de Garantías de la II República: la eliminación de miembros no juristas en la composición del Tribunal y de funciones no consustanciales a la jurisdicción constitucional, en concreto las de carácter acusatorio y punitivo. Como pronto afirmó González-Deleito Domingo (1980: 31), «la Justicia constitucional no debe asumir esas atribuciones no consustanciales con su específica y señalada misión de garantía perenne de la constitucionalidad de las leyes». Lo que nos lleva a la cuestión de la naturaleza de TC y su relación con los poderes de ejecución.

La naturaleza jurisdiccional del TC, cuestión hoy bastante aclarada, fue cuestionada en un primer momento. Los motivos esenciales que permiten afirmar que el TC es un auténtico órgano jurisdiccional (y no un órgano político bajo un antifaz de elementos jurisdiccionales) son la independencia del órgano al que se le confía específicamente la jurisdicción constitucional y la resolución de los conflictos con base en normas jurídicas, a pesar de la naturaleza política de las partes enfrentadas y de los propios conflictos. Así lo afirmó, entre muchos otros, Pérez Tremps (1985: 15). La ausencia de una definición del TC en la Constitución no permite negar la eminente función jurisdiccional del Tribunal, acompañada por la literalidad de la terminología empleada en el título IX (Peces-Barba, 1980: 2038-2047). Eso sí, una jurisdicción especial, externa a la organización judicial, independiente de los demás órganos constitucionales, solo sujeta a la Constitución y a su ley orgánica (que determinan sus límites), pudiendo acudir a las normas procesales comunes de forma supletoria (González Pérez, 1980: 75-77)28. En cualquier caso, las sentencias del TC acerca de la constitucionalidad de la reforma de 2015 insistieron en la configuración del Tribunal en el texto como «un verdadero órgano

28 Para los puntos esenciales de este debate, vid. Oubiña Barbolla (2012: 71-80). 
jurisdiccional» (STC 185/2016, de 6 de noviembre, FJ 9, y reiterado en el FJ 6 de la STC 215/2016, de 15 de diciembre, citando la anterior sentencia), al igual que los primeros autos que han aplicado el art. 92 de la LOTC en su nueva redacción, y que han supuesto la imposición de sanciones económicas a las autoridades que no han acatado las sentencias del TC en relación con la suspensión del referéndum del 1 de octubre de 2017 (AATC 126/2017, FJ 3, y 127/2017, FJ 2, ambos del 21 de septiembre, citando a su vez a la STC 185/2016). Aun así, algunos autores alertaron pronto acerca de los problemas procesales que generaba la condición de órgano jurisdiccional del supremo intérprete de la Constitución. Y algunos de esos problemas fueron atendidos en las sucesivas reformas de la LOTC. La que motiva este estudio es la décima reforma de la LOTC, segunda realizada en el año 2015, tras la reintroducción de los recursos previos de inconstitucionalidad contra los proyectos de estatutos de autonomía y contra las propuestas de reforma de los estatutos de autonomía por la LO 12/2015, de 22 de septiembre.

Ha sido frecuente el recurso a la atribución de materias prevista por el art. 161.d) de la Constitución española por parte del legislador orgánico. Así, la LO 7/1999, de 21 de abril, incorporó los conflictos en defensa de la autonomía local como producto del Pacto Local de 1997/1998, pero que la regulación de la legitimación activa dificulta su interposición como prueba su escaso número ${ }^{29}$. Finalmente, la LO 1/2010 extendió el control de constitucionalidad a las normas fiscales aprobadas por los territorios forales de Álava, Guipúzcoa y Vizcaya. Además de estas relevantes restructuraciones del sistema competencial del Tribunal, el legislador orgánico ha modificado en varias ocasiones la regulación de los procesos constitucionales, especialmente el recurso de amparo $^{30}$. La regulación del recurso de inconstitucionalidad también ha sido modificada ${ }^{31}$. Finalmente, la LO 8/2010, de 4 de noviembre, vino a res-

29 Tal es así que, a fecha de 15 de enero de 2017, la consulta en la base jurisprudencial del TC arroja como resultado diez sentencias y veinticinco autos.

30 Aunque, sin lugar a dudas, la reforma trascendental de esta acción es la realizada por la LO 6/2007, de 24 de mayo, que reforzó la dimensión de garantía objetiva de los derechos fundamentales frente a la subjetiva. Ya la LO 8/1984, de 26 de diciembre, había derogado el art. 45 sobre el recurso de amparo constitucional contra violaciones al derecho a la objeción de conciencia, y la LO 6/1988, simplificado el trámite de admisión del recurso de amparo como primera solución a la sobrecarga de trabajo que esta competencia viene generando.

31 La LO 1/2000, de 7 de enero, en aras de facilitar la colaboración entre el Estado y las comunidades autónomas y disminuir la conflictividad, amplió el plazo para interponer recursos de inconstitucionalidad de tres a nueve meses, siempre y cuando el presidente del Gobierno o los órganos colegiados ejecutivos autonómicos convoquen a la 
ponder, sin mayor fortuna, a las frecuentes dilaciones protagonizadas por el Congreso de los Diputados y el Senado en la designación de los magistrados constitucionales.

Todas las reformas han venido precedidas por la apreciación de una situación problemática manifiesta y no hipotética. Se puede afirmar, por lo tanto, que, con la reforma realizada a través de la LO 15/2015, de 16 de octubre, el legislador orgánico respondió a un problema de la jurisdicción constitucional que no se había producido. No se pueden encontrar estudios en la doctrina española que demuestren dificultades en lo que se refiere a la efectiva ejecución de las resoluciones del TC, sino que concluyen lo contrario $^{32}$. Es cierto que no se han podido evitar cuestiones problemáticas como la aprobación de leyes con contenido declarado anteriormente inconstitucional (Viver Pi-Sunyer, 2013). Tampoco se han podido evitar situaciones que han requerido la aclaración de decisiones previas ${ }^{33}$. Incluso con órganos del Poder Judicial, especialmente con el Tribunal Supremo, una relación que desgraciadamente no siempre se ha desarrollado alrededor del estricto y complejo eje de los límites dogmáticos de la jurisdicción constitucional y de la jurisdicción ordinaria (Matía Portilla, 2016). Pero es difícil afirmar que existiese una situación de resistencia a la ejecución de sus resoluciones del TC que pudiese ser valorada como problemática. Aún más si tenemos en cuenta la alta cifra de sentencias emanadas por el TC que han declarado inconstitucionales preceptos legales, aproximadamente 365 entre los años 2000 y $2017^{34}$. La comparación de esta cifra, que apenas abarca un período inferior a la mitad de los

Comisión Bilateral de Cooperación, se alcance un acuerdo para iniciar negociaciones para resolver discrepancias y se comunique al TC.

32 Por ejemplo, González Hernández (2016) afirma que «nunca se había puesto en duda el carácter de sus decisiones como ejecutables y vinculantes para todos los poderes públicos».

33 Un ejemplo lo podemos encontrar en las SSTC 147/2013, de 6 de agosto, y 125/2013, de 23 de mayo, sobre la elección a alcalde en el Ayuntamiento de Cudillero.

34 Esta cifra ha sido obtenida a partir del buscador de jurisprudencia del TC (https:// bit.ly/2DdCPMJ). El motivo por el que se limita a los años transcurridos desde el año 2000 es la inclusión en las síntesis analísticas de las resoluciones del Tribunal si las sentencias contienen una declaración de nulidad. Ello permite recuperar de forma fidedigna este dato, incluyendo en la búsqueda todos los procesos constitucionales que pueden concluir con la declaración de inconstitucionalidad de un precepto normativo. Puede ser comprobada a partir del tique de búsqueda «nVYX_SqbNQ». Aunque las memorias del TC ofrecen datos de destacado interés para el análisis de la labor del Tribunal, no señalan esta cuestión. Tampoco se han encontrado análisis empíricos en la literatura científica. 
años que ha estado en funcionamiento el TC, con las estadísticas de otros tribunales, no permite afirmar que nuestro tribunal haya sido un tribunal débil, o que haya huido del ejercicio del control de constitucionalidad con todas sus consecuencias, a diferencia del Tribunal Supremo japonés, con ocho declaraciones de inconstitucionalidad desde 1947 a 2011 (Matsui, 2011: 147). O el Tribunal Supremo danés, que apenas ha declarado nulas once disposiciones legales en 160 años (Hirschl, 2011: 450-451). Estas cifras lo sitúan más cerca del Tribunal Constitucional Federal alemán que declaró inconstitucionales 640 leyes federales o de los Länder (parcial o íntegramente) en sus primeros sesenta años (Kneip, 2016: 260-261). Y, aunque sea una afirmación meramente estadística, han sido abundantes las ocasiones en las que el Tribunal ha podido encontrar la oposición de las autoridades públicas.

En cualquier caso, el legislador orgánico ha modificado en esta última reforma los arts. 80, 87, 92 y 95.4 de la LOTC, que en conjunto redundan en una auténtica manifestación procesal de la supremacía del TC (Pérez Tremps, 2016: 26-28). En primer lugar, se establece el carácter supletorio de las disposiciones de la Ley de la Jurisdicción Contencioso-Administrativa en la ejecución de resoluciones. En cuanto al obligado cumplimiento de las resoluciones del TC por parte de los poderes públicos, el legislador afirma su carácter ejecutivo y añade la posible notificación personal de estas a cualquier autoridad o empleado público. Además, también afirma la centralidad del propio Tribunal en el cumplimiento efectivo de sus resoluciones, estableciendo un régimen propio en caso de incumplimiento. Conforme a este régimen, el Tribunal podrá requerir información a todos los sujetos que estén obligados a dar cumplimiento a sus resoluciones, tanto a instancia de parte como de oficio, y en caso de que considere que no se está dando debido cumplimiento, podrá imponer multas coercitivas de 3000 a 30000 euros, que cabe reiterar hasta el efectivo acatamiento. Podrá inclusive suspender en sus funciones a las autoridades públicas responsables si no cumplen con la efectiva observancia de sus resoluciones. También podrá recurrir a la ejecución sustitutoria para dar cumplimiento a las resoluciones originadas en procesos constitucionales, solicitando la colaboración del Gobierno de la nación, así como recabar el testimonio de particulares para exigir responsabilidades penales. Finalmente, en los casos de «ejecución de las resoluciones que acuerden la suspensión de las disposiciones, actos o actuaciones impugnadas y concurrieran circunstancias de especial transcendencia constitucional, el Tribunal, de oficio o a instancia del Gobierno, adoptará las medidas necesarias para asegurar su debido cumplimiento sin oír a las partes».

Esta batería de medidas sorprende. El «jurista persa» o analista descontextualizado podría deducir que el legislador orgánico ha tenido que reaccionar a una situación generalizada de resistencia a la ejecución, o bien a la 
necesidad de suplir un agudo déficit en las posibilidades para la ejecución de las resoluciones del intérprete supremo de la Constitución. Sin embargo, no se daba ninguna de las dos situaciones que se acaban de plantear. En el título VII de la LOTC, dedicado a las "disposiciones comunes sobre procedimiento", encontramos los preceptos cuyo objeto es la obligatoriedad de la ejecución de las resoluciones del TC, derivada del art. $164 \mathrm{CE}$, destinado al valor de las sentencias constitucionales y al mandato de publicación de sus sentencias. Hasta ese momento, el TC contaba con el doble reconocimiento de la obligación de cumplir sus sentencias por parte de los poderes públicos (art. 87.1) y la obligación de los juzgados y tribunales de prestarle auxilio de modo preferente y urgente (art. 87.2). Este doble reconocimiento ha operado como un refuerzo de la posición institucional del TC (Huelin Martínez de Velasco, 2001), reflejo de su primacía procesal. Como es obvio, la falta de cumplimiento de las resoluciones del Tribunal generaría responsabilidades penales, civiles o disciplinarias (Almago Nosete, 1989: 564). Además, como ya ha sido observado, el TC siempre ha dispuesto como medio para garantizar la ejecución la posibilidad de decidir sobre quién ha de ejecutar la resolución y sobre las incidencias en la ejecución (art. 92 LOTC). Por lo tanto, ha dispuesto del poder de ejecución de sus propias facultades (ibid.: 587), así como de la imposición de multas coercitivas a cualquier persona que incumpla sus requerimientos (art. 95.4, modificado por la LO 6/2007, de 24 de mayo, aumentando los importes). Y tras la reforma realizada por la LO 6/2007, de 24 de mayo, tiene la capacidad de declarar nulas las resoluciones que contravengan sus decisiones al ejecutarlas, reforzando la posición institucional del TC, permitiendo que sea el propio Tribunal el que delimite su jurisdicción protegiéndose ante cualquier intromisión (Moreno Fernández, 2010; Corte Heredero, 2010).

Por ello, no se puede hablar ni de ausencia de medios de ejecución ni de insuficiencia de estos. En general, la valoración de la situación anterior es positiva (aparte de los datos estadísticos aportados anteriormente), pudiéndose considerar que la carencia de una ley procesal constitucional y de mayor concreción en este sentido ha aportado flexibilidad (Lozano Miralles y Saccomanno, 2000: 305), sin que esto se tradujese en un TC inerme. Todo lo contrario, se ha visto como el art. 35 de la ley que regula el Tribunal Constitucional Federal alemán le permitió a esta institución responder doctrinalmente con autonomía a los retos que se fueron interponiendo en el ejercicio de su jurisdicción, sin necesidad del auxilio del legislador. Una disposición normativa trasladada a nuestro ordenamiento y de la que ha dispuesto nuestro Tribunal, que ha ejercido una auténtica libertad para configurar jurisdiccionalmente su derecho procesal, estando justificado el uso del término «autonomía procesal» originado en la doctrina alemana como lo hace P. Rodríguez Patrón (2001). Y tampoco se puede olvidar que los procesos constitucionales han estado deter- 
minados por un formalismo atenuado (Montoro Puerto, 1991: 167), aunque la tendencia hacia la positivización de cada vez más elementos también es observable.

Es innegable que la ejecución es parte de la jurisdicción. La potestad jurisdiccional reside tanto en la potestad de decisión, resolviendo de forma definitiva el conflicto, como en potestad de ordenación del proceso y en la potestad de coerción, dirigida a hacer efectiva la sentencia (Moreno Catena y Cortés Domínguez, 2015: 116). Esta característica es propia de ordenamientos jurídicos avanzados, en estadios de profunda maduración y perfeccionamiento, fenómeno que se tiende a generalizar cuando el responsable del análisis parte de estas realidades. Como ilustró Shapiro (1986: 13), en la mayoría de las sociedades los instrumentos de ejecución de resoluciones a disposición de los tribunales no van más allá del cumplimiento voluntario, cuando no la autocomposición. Situación que nunca ha sido la de nuestra jurisdicción constitucional, como ha podido observarse.

El problema de la última reforma radica en los términos en los que se ha configurado, y en alguno de los instrumentos otorgados, tanto en la conveniencia como por el difícil casamiento con la naturaleza del TC. Y las dificultades son, por supuesto, cualitativas, pero también pueden llegar a ser cuantitativas. Quizá esta última vertiente sea la que menos extensión exige, pero no por ello es menos relevante de cara a garantizar la eficiencia del Tribunal. Hoy somos plenamente conscientes de que la jurisdicción constitucional es un bien muy escaso, lo que ha conducido hacia su racionalización tanto a nivel comparado (Wahl y J. Wieland 1997) como en nuestro ordenamiento jurídico, constituyendo un inmejorable ejemplo la discutidísima objetivación de la fase de admisión del recurso de amparo realizada en 2007 (Montesinos Padilla, 2017).

\section{LA LO 15/2015, DE 16 DE OCTUBRE, ANTE EL TRIBUNAL CONSTITUCIONAL}

Nuestro Tribunal ha tenido oportunidad de manifestarse sobre estas dificultades relacionadas con la naturaleza de la jurisdicción constitucional y su difícil encaje en el modelo de jurisdicción constitucional establecido en la Constitución de 1978. Poco después de cumplido el primer aniversario de esta última reforma, el pleno del TC resolvió en su Sentencia 185/2016, de 3 de noviembre, el recurso de inconstitucionalidad interpuesto por el Gobierno vasco. Hay que tener en cuenta que este fue el segundo recurso de inconstitucionalidad que se interpuso, resolviéndose el del Gobierno de la Generalitat el 15 de diciembre de 2016. Llama la atención que no haya acumulado los dos procesos constitucionales tal y como permite el art. 83 LOTC. El motivo 
aportado por el TC es que el recurso proveniente del Gobierno vasco plantea la inconstitucionalidad de la reforma por suponer «una desnaturalización del modelo de jurisdicción constitucional diseñado por el constituyente» de 1978, razón que hace necesario resolver este recurso antes y que no resultase oportuno acumularlos (Sentencia de 15 de abril de 2016, FJ 4).

Esta es la cuarta reforma de la LOTC que ha sido sometida al control de constitucionalidad, sin que el supremo intérprete constitucional haya encontrado tacha de inconstitucionalidad en ninguna de ellas. No se va a reseñar en esta contribución el alegado vicio procedimental alegado en ambos recursos de inconstitucionalidad por la tramitación por el procedimiento de urgencia y en lectura única. A los efectos de este trabajo basta decir que el Tribunal aplica su doctrina sobre el respeto a la autonomía de las Cámaras legislativas sobre los procedimientos que en ellas se desarrollan, y en concreto, el respeto al criterio de oportunidad de la Mesa del Congreso de Diputados y de su Pleno cuando se proponen y aprueban tramitaciones de proposiciones de ley por este cauce (STC 185/2015, FJ 3).

Son de mayor interés para este estudio los motivos en los que funda el TC el rechazo a las diversas alegaciones de inconstitucionalidad material de ambos recursos, reiterando el Tribunal la doctrina que vamos a reseñar en la Sentencia de 15 de diciembre de 2016. En primer lugar, con respecto a la supuesta extralimitación del legislador orgánico en relación con la habilitación del art. $165 \mathrm{CE}$ y el cambio de naturaleza y funciones del TC, alterando el equilibrio de poderes, el Tribunal, recordando que su juicio solo puede ser de constitucionalidad, rechaza la argumentación por su generalidad (STC 185/2015, FJ 7). Y continúa afirmando el carácter abierto del modelo de jurisdicción constitucional, siendo responsabilidad del legislador orgánico la concreción de muchos de sus elementos, extrayendo ejemplos de su doctrina, como la regulación de la figura del presidente, la atribución abierta de procesos y su regulación, incluidos ciertos aspectos de la legitimación activa (STC $185 / 2015$, FJ 8).

El Tribunal rechaza que la ausencia de mención en materia de ejecución de las resoluciones del Tribunal implique que sea una cuestión vedada por el constituyente. Sostiene que es una «cualidad inherente a la función de administrar justicia» (STC 185/2015, FJ 9), sin que exista disposición constitucional que impida que se establezca un proceso incidental que contenga instrumentos cuyos destinatarios puedan ser los más altos órganos del Estado y de las comunidades autónomas (STC 185/2015, FJ 10). Tampoco observa vulneración del principio de legalidad penal ni del régimen de aforamientos en la suspensión de autoridades públicas, descartando el carácter punitivo de esta medida, dado que su finalidad es asegurar el efectivo cumplimiento de la resolución del Tribunal y no castigar a la autoridad pública renuente que obs- 
taculice la ejecución (STC 185/2015, FF. JJ. 11-15). Finalmente, de nuevo la exclusiva finalidad de garantizar el efectivo cumplimiento de las resoluciones como único título legitimador de las nuevas medidas de ejecución es utilizada como argumento para rechazar la inconstitucionalidad de la ejecución sustitutoria mediante la colaboración del Gobierno de la nación.

Si bien estas cuestiones sobre la constitucionalidad de los nuevos instrumentos han sido resueltas por nuestro intérprete supremo de la Constitución, su argumentación dista de ser satisfactoria. Los votos particulares de los magistrados Adela Asúa Batarrita, Fernando Valdés Dal-Ré y Juan Antonio Xiol Ríos, junto con los elementos que se han intentado aportar en esta contribución, ayudan a que se alcance esta conclusión. En concreto, la posible suspensión de las autoridades fuerza al Tribunal a apartarse, por poco que sea, de su posición natural de juez de normas y de la regularidad de la reproducción normativa en los términos kelsenianos que he reseñado anteriormente. Igual de especialmente relevantes son las dificultades que plantea el mecanismo de ejecución subsidiaria, distribuyendo la titularidad de la medida en el Tribunal y la ejecución en el Gobierno de la nación. Se obtendrá así seguro la legitimidad jurídica ex ante para la actuación política. Pero se desconocen los costes que también va a asumir la legitimidad del TC.

\section{LA LO $15 / 2015$, DE 16 DE OCTUBRE, ANTE LA COMISIÓN DE VENECIA}

Estas preocupaciones están recogidas en la Opinión 827/2015 de la Comisión de Venecia del Consejo de Europa de 10-11 de marzo de 2017. Pero antes de analizarla es conveniente revisar el informe sobre la posición de España sobre la LO 15/2015, de 16 de octubre, de 29 de septiembre de 2016.

El Gobierno defiende la reforma con base en sucesivos requerimientos del TC desde 1991 para la subsanación de defectos en su derecho procesal relacionados con la ejecución de sentencias. Sin embargo, el informe no recoge ejemplos concretos de resistencias por parte de autoridades públicas a acatar las resoluciones del Alto Tribunal, sino que menciona la ausencia de un mecanismo para la ejecución efectiva de las resoluciones del Tribunal Europeo de Derechos Humanos (TEDH).

El informe no señala casos concretos de dificultades a la hora de ejecutar las resoluciones del TC que se deben a la resistencia por parte de autoridades $\mathrm{u}$ órganos públicos, ni tampoco de llamadas al legislador desde el Tribunal para que atienda una situación de ese tipo. En su lugar, cita la Resolución 1/XI, de 9 de noviembre de 2015, del Parlamento de Cataluña, en la que, además de afirmar la soberanía de esta institución como expresión del poder constituyente, expresa su intención de ignorar las decisiones del Estado español y, en concreto, de su TC. 
Para apoyar la solución por la que optó el legislador orgánico, se acude al derecho constitucional comparado, específicamente a los reconocidos como referentes de nuestro TC, los tribunales constitucionales alemán y austriaco. El informe también cita el ejemplo suizo, solución de menor valor, dado que, como el propio informe indica, en esa jurisdicción es al Consejo Federal y a la Asamblea federal a los que les incumbe tomar las medidas que consideren necesarias en caso de un desacatamiento de una resolución del Tribunal Supremo Federal por parte de una autoridad cantonal. También incluye a Estonia y a Ucrania. En el primer caso no queda claro que sea su respectivo Alto Tribunal el que resuelve directamente acerca de las medidas a tomar en relación con la ejecución de sus resoluciones. Y sobre Ucrania, se señala una propuesta de reforma constitucional que capacita al presidente para intervenir en caso de que algún órgano público atente contra la soberanía estatal o la integridad territorial. Más allá de los ejemplos alemán y austriaco, es difícil encontrar el interés comparativo en el resto de casos alegados.

Finalmente, el informe señala la existencia de justificaciones suficientes que avalaban la aprobación parlamentaria urgente y por lectura única, e insiste en que tiene su origen en una propuesta y no en un proyecto de ley. Y sobre las distintas medidas, además de que están dirigidas hacia la garantía de la supremacía constitucional en un Estado de derecho, se sostiene que ninguna de ellas tiene carácter punitivo, se ajustan al principio de proporcionalidad y cesarán una vez la autoridad dé cumplimiento a lo requerido por el Tribunal.

La Opinión 827/2015 de la Comisión de Venecia, además de haber generado todo tipo de lecturas desde los medios de comunicación españoles dependiendo de qué elemento escogiesen para el enfoque de la noticia, aporta elementos de destacado interés para este estudio. En primer lugar, afirma que la identificación del proceso secesionista en Cataluña como la causa de la reforma era una posición compartida por los diferentes interlocutores entrevistados por la delegación de la Comisión de Venecia que se trasladó a España para elaborar los trabajos previos a la Opinión (párrafo 12). Ratifica los datos provenientes del derecho constitucional comparado. La opinión sostiene que, en la actualidad, no existe un estándar europeo en lo que a la imposición de medidas ejecutivas se refiere. De hecho, apenas el de Moldavia tiene capacidad para imponer multas administrativas (párrafo 26). Solo en las leyes de los tribunales constitucionales de Albania, Armenia y Ucrania, además de Moldavia, se establecen sanciones civiles o penales en caso de desacatamiento de sus resoluciones. Y únicamente el de Montenegro cuenta con un mecanismo para la supervisión del cumplimiento de sus resoluciones (párrafo 20). Se insiste en que en las democracias arraigadas estas situaciones han sido raras. De ahí que no existan medidas legislativas explícitas (párrafo 24). Por lo que el Tribunal 
español se ha situado tras la décima reforma de su ley orgánica en la excepción europea en esta materia.

Si el análisis de la Comisión de Venecia desde el derecho constitucional comparado es esclarecedor, aún más es el estudio de las medidas adoptadas por el legislador orgánico. Los aspectos problemáticos se centran en atribuir la responsabilidad de asegurar el cumplimiento general de sus resoluciones al Tribunal, elemento que no tiene equivalente en ningún otro Alto Tribunal europeo según la opinión (párrafo 38). Sobre el poder para anular cualquier decisión de un órgano público que contradiga una resolución del Tribunal, la opinión expresa dos consideraciones. Por un lado, que el Tribunal no debe actuar de oficio, sino siempre tras el requerimiento de una parte, a riesgo de no hacerlo así de comprometer su neutralidad. Además, esta tarea podría suponer una sobrecarga para el Tribunal si este órgano va a supervisar cualquier incumplimiento individual de sus decisiones.

En cuanto a las sanciones económicas, dado el alto importe que pueden llegar a alcanzar, la Comisión advierte de que podrían llegar a ser consideradas como cargas penales de acuerdo con el art. 6 de la Convención Europea de Derechos Humanos, al menos en los casos de particulares y empleados públicos, no así si se trata de autoridades públicas. Nuestro Tribunal ha insistido en negar su carácter punitivo (SSTC 185/2016 y 2015/2016) y el TEDH inadmitió por falta manifiesta de fundamentación la demanda presentada por una de las personas designadas como miembros de la Administración electoral del referéndum del 1 de octubre de 2017 (caso Aumatell i Arnau v. España, Decisión de 4 de octubre de 2018) ${ }^{35}$. La Comisión advierte también sobre los valladares que pueden producirse en el momento de aplicar estas sanciones. Expresa sus dudas de que estas sanciones pueden aplicarse de forma efectiva, teniendo en cuenta que se trata de autoridades públicas que ya se han negado al cumplimiento de las resoluciones del Tribunal, cómo va este a imponerles el cumplimiento de las consecuentes sanciones económicas, careciendo de medios para hacerlo. Este procedimiento, en vez de reforzar la autoridad del Tribunal, la minaría (párrafo 53).

Pero aún más problemática para la Comisión resulta la eventual suspensión de autoridades públicas como sanción. La doctrina española sigue expresando dudas acerca de la constitucionalidad de esta medida, a pesar de que hayan sido rechazadas por el Alto Tribunal en sus sentencias 185/2016 y

35 Para un comentario se puede acudir a Queralt Jiménez (2018). «Estrasburgo se estrena en el "Procés" con una inadmisión». Agenda Pública. Disponible en: http:// agendapublica.elpais.com/estrasburgo-se-estrena-en-el-proces-con-una-inadmision/ (último acceso: 5 de noviembre de 2018). 
215/2016 (Villaverde Menéndez, 2016). Y a las sombras sobre su constitucionalidad, la opinión añade cuestiones acerca de su convencionalidad en caso de su aplicación a cargos públicos electos (párrafos 56 y 57). Pero incluso se podría plantear una paradoja situación práctica: el Tribunal tendría que interrumpir la sanción de suspensión para que la autoridad tenga oportunidad de acatar las resoluciones del Tribunal, en caso de que la autoridad quiera hacerlo. Situación que podría convertirse en un irresoluble bucle «absurdo» en palabras de la Comisión (párrafos 59 y 60).

Por estos motivos la Comisión de Venecia concluye recomendando el replanteamiento de la atribución de la responsabilidad directa y general sobre la ejecución de sus resoluciones al TC. Y, como vamos a ver a continuación, el contraste de la opinión de la Comisión con la efectividad de los primeros siete incidentes de ejecución estimados tras la reforma refuerza su recomendación.

\section{LA APLICACIÓN DE LOS NUEVOS PODERES DE EJECUCIÓN}

Por mucho que la reforma de la LOTC que aquí se comenta se hiciese con carácter general y sin estar dirigida, al menos de forma explícita, a unas circunstancias específicas, hasta el momento, todos los incidentes de ejecución estimados están relacionados con el proceso de secesión catalán, y los siete han estado promovidos por el Gobierno de España (se cumple en este sentido con la recomendación de la Comisión de Venecia). Irremediablemente, los autos también reflejan la progresiva escalada en el conflicto.

En la primera decisión de ejecución, el ATC 141/2016, de 19 julio, el Tribunal anuló la Resolución 5/XI del Parlamento de Cataluña, de 20 de enero de 2016, que suponía la creación de diversas comisiones parlamentarias, incluyendo una de estudio del proceso constituyente. El Tribunal estimó que dicha resolución desarrollaba la Resolución del Parlamento catalán 1/XI, de 9 de noviembre de 2015, que iniciaba el proceso para la creación de un Estado catalán independiente, y que fue declarada inconstitucional por la STC 259/2015, de 2 de diciembre. El FJ 7 de este auto conmina a los poderes públicos y a sus titulares a responsabilizarse de que las comisiones parlamentarias no se excedan en su actuación del marco constitucional y estatutario.

Los «absurdos» bucles en los que se podía ver envuelto el TC advertidos por la opinión de la Comisión de Venecia no tardaron en llegar, a medida que el Parlamento de Cataluña avanzaba en el desarrollo de su declarada inconstitucional Resolución 1/XI, de 9 de noviembre de 2015. Así, el primer auto no fue suficiente para impedir las actividades de la Comisión parlamentaria para el estudio del proceso constituyente, de modo que fue necesaria una resolución del Tribunal que declarase inconstitucional la resolución del Parlamento de Cataluña que ratificó las conclusiones de la comisión de estudio 
del proceso constituyente, cuya constitución fue declarada inconstitucional. El ATC 170/2016, de 6 de octubre, advirtió personalmente a la presidenta y al secretario general del Parlamento de Cataluña, junto con el resto de miembros de la Mesa del Parlamento, al presidente y demás miembros del Consejo de Gobierno de la Generalitat de Cataluña, y solicitó el testimonio de particulares, abriendo la posibilidad de iniciar acciones penales por parte del Ministerio Fiscal, acuerdos que va a reiterar en los siguientes autos. Apenas cinco meses más tarde, a través de un nuevo auto (ATC 24/2017, de 14 de febrero), declaró nulo el contenido de la Resolución del Parlamento de Cataluña 306/XI, de 6 de octubre de 2016, relacionado con el referéndum y el proceso constituyente. Y mediante los AATC 123/2017 y 124/2017, ambos de 19 de septiembre, declaró nulos los acuerdos de la Mesa del Parlamento de Cataluña de admisión a trámite de la proposición de ley del referéndum de autodeterminación y de la proposición de ley de transitoriedad jurídica y fundacional de la república, respectivamente. En todos ellos el Tribunal insiste en que el Parlamento de Cataluña puede promover una hipotética reforma de la Constitución, norma a la que los poderes públicos deben fidelidad y que aúna el principio democrático y la legalidad constitucionalidad, siendo la segunda garantía, y no límite, del primero.

Finalmente, en los autos 126/2017, de 21 de septiembre, y 127/2017, de 22 de septiembre, el Tribunal impuso por primera vez sanciones económicas por su responsabilidad en los actos para la organización de la consulta declarada inconstitucional a los síndicos electorales y al secretario general de la Vicepresidencia y de Economía y Hacienda, y a la jefa de área de procesos electorales y consultas populares. Los importes de las multas, de periodicidad diaria, dependiendo de las autoridades, ascendían a los 6000 y 12000 euros. La respuesta de los titulares de dichos cargos públicos fue la renuncia o la destitución desde el Gobierno de la Generalitat ${ }^{36}$.

En palabras de Antoni Bayona, entonces letrado mayor del Parlamento catalán: «[...] a causa de las resoluciones adoptadas a lo largo de la legislatura, el mismo Parlamento había propiciado que sus márgenes normales de actuación quedaran reducidos por la intervención del Tribunal Constitucional y sus severas advertencias de responsabilidad de los miembros de la Mesa si volvían a desobedecer sus resoluciones» (Bayona, 2019: 272). Pero la eficacia

36 El secretario general de la Vicepresidencia y de Economía y Hacienda fue detenido por la Guardia Civil el 20 de septiembre de 2017, acusado de sedición, desobediencia, prevaricación y malversación, por los actos relacionados con la organización de la consulta del 1 de octubre de 2017. Véase: https://bit.ly/2QNCsQS (último acceso: 5 de noviembre de 2018). 
de la intervención del TC no debe hacernos olvidar sus costes, de los que nos alertaban los magistrados Fernando Valdés Dal-Ré, Juan Antonio Xiol Ríos y María Luisa Balaguer Callejón en su voto particular concurrente al Auto 126/2017, de 21 de septiembre:

Descender a la utilización de tales instrumentos de ejecución acerca en exceso nuestra jurisdicción a la jurisdicción ordinaria, haciéndonos perder parte de nuestra propia esencia, al tiempo que busca con tales instrumentos resolver conflictos de base política, siendo evidente la falta de adecuación de tales instrumentos al objetivo perseguido mediante el recurso a los mismos: el aseguramiento del respeto al texto constitucional.

\section{CONCLUSIÓN}

El refuerzo de los poderes de ejecución del TC no ha impedido que la actual crisis constitucional se haya acabado materializando con toda su virulencia. El objetivo, no explicitado públicamente, pero sí reconocido por los diferentes actores, de atajar el movimiento secesionista sin llegar a activar la coacción estatal prevista en el art. 155 CE no se ha alcanzado. Y, sin embargo, la autoridad del Tribunal sí que ha resultado afectada. Con esta reforma el legislador orgánico ha caído en el peligroso olvido de muchas lecciones aparentemente bien asumidas, concentrando las funciones, la titularidad y buena parte de los procesos de aplicación de los nuevos instrumentos de ejecución de sus resoluciones en el propio TC.

Ha sido la primera vez que se realiza una reforma del Tribunal sin que se hubiese constatado un problema real. No se tuvieron en cuenta los óptimos resultados que hasta ahora había dado el desarrollo de la autonomía procesal del TC. Y tampoco que otros órganos del Estado pueden ejecutar sus resoluciones, mientras este ejerce su potestad original para determinar los órganos y la forma en la que han de ejecutar sus resoluciones.

Este refuerzo ejecutivo del Tribunal le ha situado como protagonista, y, en ciertos momentos, casi como solista, de la defensa de la Constitución, cuando nuestro sistema constitucional reparte esta responsabilidad entre todas las autoridades públicas y la ciudadanía. Además, la reforma ha avanzado en la senda que dirige hacia el establecimiento de los cauces jurisdiccionales como el instrumento prácticamente universal para solucionar todos los conflictos, ignorando su diversa naturaleza. Esta reforma se entiende como un nuevo episodio de la huida de la toma de decisión política para evitar sus responsabilidades, trasladándolas a los órganos jurisdiccionales. Y lo que es mucho más importante, ha comprometido la significación integradora que ha 
de presidir el ejercicio de las funciones del TC, como recordó García-Pelayo en su discurso como presidente del Tribunal con motivo de su constitución pública. Difícilmente se puede sostener este argumento si el Tribunal tiene que actuar activamente en la imposición de su decisión, y si encuentra oídos sordos en las autoridades a las que se dirige. Como advirtió Tomás y Valiente en su discurso de despedida con ocasión de la renovación del Tribunal en 1992, si no se identifican correctamente aquellos problemas políticos que sí pueden resolverse por métodos jurisdiccionales, y se separan de aquellos que solo pueden ser resueltos por cauces políticos, se está corriendo el riesgo de tomar la senda más directa para «destruir una institución cuya autoridad es la autoridad del Derecho».

Esta reforma ha querido reforzar al Tribunal como parte efectiva de nuestra Constitución, pero a costa de comprometer el que siga siendo reconocida como una de sus partes dignificadas. El legislador orgánico ha incidido en la faceta jurisdiccional del TC, otorgándole poderes de ejecución que o bien son auténticamente excepcionales, o bien lo aproximan a un tribunal ordinario. No debe asumirse el recurso a los instrumentos de ejecución como parte de la normalidad del funcionamiento del sistema, sino como un mecanismo de excepción. Indudablemente, y como muchos han advertido, las instituciones ganan o pierden prestigio por lo que hacen, pero también por lo que con ellas se hace.

\section{Bibliografía}

Acosta Sánchez, J. (1998). Formación de la Constitución y Jurisdicción constitucional: Fundamentos de la Democracia Constitucional. Madrid: Tecnos.

Almago Nosete, J. (1989). Justicia constitucional. Comentarios a la Ley Orgánica del Tribunal Constitucional. Valencia: Tirant lo Blanch.

Álvarez Conde, E. (2018). La ejecución de las resoluciones del Tribunal Constitucional. ¿Un cambio de modelo de justicia constitucional? Revista de Derecho Politico, 101, 661-701.

Arzoz Santisteban, X. (2016). Los poderes de ejecución de los tribunales constitucionales alemán y austriaco. Revista Española de Derecho Constitucional, 108, 13-49.

Bassols Coma, M. (2010). El Tribunal de Garantías Constitucionales de la II República: La primera experiencia de la justicia constitucional en España. Madrid: Boletín Oficial del Estado.

Baum, L. (2016). The Implementation of U.S. Supreme Court Decisions. En R. Rogowski y T. Gawron (eds.). Constitutional Courts in Comparison: The U.S. Supreme Court and the German Federal Constitutional Court. New York: Berghahn Books. 
Bayona Rocamora, A. (2019). No todo vale. La mirada de un jurista en las entrañas del procés. Barcelona: Ediciones Península.

Beard, C. A. (1912). The Supreme Court: Usurper or Grantee? Political Science Quarterly, 27 (1), 1-35.

Bickel, A. M. (1962). The Last Dangerous Branch: The Supreme Court at the Bar of Politics. New Haven: Yale University Press.

Breyer, S. (2017). Cómo hacer funcionar nuestra democracia. El punto de vista de un juez. Ciudad de México: Fondo de Cultura Económica.

Brinks, D. M. y Blass, A. (2017). Rethinking judicial empowerment: The new foundations of constitutional justice. International Constitutional Law Journal, 15 (2), 296-331.

Cappelletti, M. (1979). The Mighty Problem of Judicial Review and the Contribution of Comparative Analysis. Legal Issues of Economic Integration, 2, 1-29.

Chen, H. Y. A. y Poiares Maduro, M. (2013). The Judiciary and Constitutional Review. En M. Tushnet, T. Fleiner y C. Saunders (eds.). Routledge Handbook of Constitutional Law (pp. 97-109). London; New York: Routledge.

Collings, J. (2015). Democracy's Guardians: A History of the German Federal Constitutional Court. Oxford: Oxford University Press.

Constant, B. (1814). Réflexions sur les constitutions: La distribution de pouvoirs, et les garanties en dans une monarchie constitutionelle. Paris: Imprimiere Hocquet.

Corte Heredero, N. (2010). Artículo 92. En J. J. González Rivas (dir.-coord.). Comentarios a la Ley orgánica del Tribunal Constitucional. Madrid: La Ley.

Cortes Generales (1980). Tribunal Constitucional: Trabajos Parlamentarios. Madrid: Publicaciones de las Cortes Generales.

Dahl, R. A. (1957). The Concept of Power. Behavioral Science, 2 (3), 201-215.

De Visser, M. (2015). Constitutional Review in Europe: A Comparative Analisys. Oxford: Hart Bloomsbury.

Eisenmann, C. (1986). La Justices constitutionnelle et la Haute Cour Constitutionnelle D'Autriche. Paris: Editeur Economica.

Favoreu, L. (1995). Los Tribunales Constitucionales. Barcelona: Ariel.

Feinman, J. M. (2012). Supreme Court Decisions. New York: Penguin Books.

Fernández Farreres, G. (2018). Las nuevas facultades del Tribunal Constitucional para asegurar el cumplimiento de sus resoluciones. Revista Española de Derecho Constitucional, 112, 15-44.

Fernández Segado, F. (2013). Sir Edward Coke, El Bonham's Case y la Judicial Review. En Libro de ponencias y comunicaciones del XI Congreso Iberomericano de Derecho Constitucional "Jorge Carpizo».

Ferreres Comella, V. (2009). Una defensa del modelo europeo de control de constitucionalidad. Madrid: Marcial Pons.

García Balaunde, D. (2009), Kelsen en París: Una ronda en torno al modelo concentrado. Anuario Iberoamericano de Derecho Constitucional, 13, 307-332.

García de Enterría, E. (1981). La posición jurídica del Tribunal Constitucional en el sistema español: Técnicas y perspectivas. Revista Española de Derecho Constitucional, 1 (1), 35-131. 
Gardbaum, S. (2018). What Makes for More or Less Powerful Constitutional Courts? Duke Journal of Comparative and International Law, 29 (1).

Gawron, T. y Rogowski, R. (2016). Implementation of German Federal Constitutional Court Decisions: Judicial Orders and the Federal Legislature. En R. Rogowski y T. Gawron (eds.). Constitutional Courts in Comparison: The U.S. Supreme Court and the German Federal Constitutional Court (pp. 1951-1987). New York: Berghahn Books.

Ginsburg, T. (2008). The Global Spread of Constitutional Review. En K. E. Whittington, R. D. Kelemen y G. A. Calderia (eds.). The Oxford Handbook of Law and Politics. Oxford: Oxford University Press.

Ginsburg, T. y Versteeg, M. (2013). Why do Countries Adopt Contitutional Review. Journal of Law, Economics, and Organization, 29 (6), 587.

González-Deleito Domingo, N. (1980). Tribunales Constitucionales: Organización y funcionamiento. Madrid: Tecnos.

González Hernández, E. (2016). El artículo 155 CE y la LO 15/2015 de 17 de octubre de reforma de la LOTC: ¿ineludible reciprocidad o círculo perverso? Teoría y Realidad Constitucional, 36, 529-557.

González Pérez, J. (1980). Derecho Procesal Constitucional. Madrid: Civitas.

Hall, M. E. K. (2011). The Nature of the Supreme Court Power. Cambridge: Cambridge University Press.

Hamilton, A. (2004). El Federalista. México D. F.: Fondo de Cultura Económica.

Harding, A. y Leyland, P. (eds.) (2009). Constitutional Courts: A Comparative Study. London: Wildy, Simmonds and Hill Publishing.

Hirschl, R. (2011). The Nordic counternarrative: Democracy, human development, and judicial review. International Journal of Constitutional Law, 9 (2), 449-469. Disponible en: https://doi.org/10.1093/icon/mor034.

Huelin Martínez de Velasco, J. (2001). Artículos 87 y 92. En J. L. Requejo Pagés. Comentarios a la Ley Orgánica del Tribunal Constitucional. Madrid: Tribunal Constitucional; Boletín Oficial del Estado.

Issacharoff, S. (2015). Fragile Democracies: Contested Power in the Era of Constitutional Courts. Cambridge: Cambridge University Press.

Kelsen, H. (1942). Judicial Review of Legislation: A Comparative Study of the Austrian and the American Constitution. Journal of Politics, 4, 183-200.

- (1995). Teoría General del Derecho y del Estado. México D. F.: Universidad Autónoma de México.

- (2011). La garantía jurisdiccional de la Constitución (la justicia constitucional). Anuario Iberoamericano de Justicia Constitucional, 15, 249-300.

Kneip, S. (2016). The Impact of the German Federal Constitutional Court Consolidation and Quality of Democracy. En R. Rogowski y T. Gawron (eds.). Constitutional Courts in Comparison: The U.S. Supreme Court and the German Federal Constitutional Court (pp. 254-281). New York: Berghahn Books.

Lozano Miralles, J. y Saccomanno, A. (2000). El Tribunal Constitucional: Composición y principios juridico-organizativos (el aspecto funcional). Valencia: Tirant lo Blanch. 
Matía Portilla, F. J. (2016). Las tensas relaciones entre el Tribunal Supremo y el Tribunal Constitucional y los límites de la (legítima) discrepancia entre ellos. Revista de Derecho Politico, 97, 13-48.

Matsui, S. (2011). The Constitution of Japan. A Contextual Analysis. Oxford; Portland: Hart Publishing.

Montesinos Padilla, C. (2017). La tutela multinivel de los derechos desde una perspectiva jurídico procesal: el caso español. Valencia: Tirant lo Blanch.

Montoro Puerto, M. (1991). Jurisdicción constitucional y procesos constitucionales. Madrid: Colex.

Moreno Catena, V. y Cortés Domínguez, V. (2015). Introducción al Derecho Procesal. Valencia: Tirant lo Blanch.

Moreno Fernández, J. I. (2010). Artículo 87. En J. J. González Rivas (dir.-coord.). Comentarios a la Ley orgánica del Tribunal Constitucional. Madrid: La Ley.

Oubiña Barbolla, S. (2012). El Tribunal Constitucional: Pasado, presente y futuro, Valencia: Tirant lo Blanch.

Peces-Barba Martínez, G. (1980). El Tribunal Constitucional (vol. 3). Madrid: Instituto de Estudios Fiscales.

Pérez Tremps, P. (1985). Tribunal Constitucional y Poder Judicial. Madrid: Centro de Estudios Políticos y Constitucionales.

- (2016). Sistema de Justicia Constitucional. Cizur Menor: Civitas.

Plucknett, F. (1926-1927). Bonham's Case and Judicial Review. Harvard Law Review, 30-70.

Queralt Jiménez, A. (2018). Estrasburgo se estrena en el «Procés» con una inadmisión. Agenda Pública [blog], 4-10-2018. Disponible en: https://bit.ly/2NMyIwa.

Rodríguez-Patrón, P. (2001). La libertad del Tribunal Constitucional alemán en la configuración de su derecho procesal. Revista Española de Derecho Constitucional, 62, 125-178.

Rosenfeld, M. (2004). Constitutional Adjudication in Europe and in the United States: Paradoxes and Contrasts. International Constitutional Law Journal, 2 (4), 633-668.

Rubio Llorente, F. (1992). Seis tesis sobre la Jurisdicción constitucional en Europa. Revista Española de Derecho Constitucional, 35, 9-39.

Schabe, J. (2009). Jurisprudencia del Tribunal Constitucional Federal Alemán. Extractos de las sentencias más relevantes. Berlín: Konrad Adenauer Stiftung.

Shapiro, M. (1986). Courts: Comparative and Political Analysis. Chicago: The University of Chicago Press.

Stone Sweet, A. (2012). Constitutional Courts. En M. Rosenfeld y A. Sajó. The Oxford Handbook of comparative Constitutional Law. Oxford: Oxford University Press.

Thorne, S. E. (1938). Dr. Bonham's Case. Law Quarterly Review, 54, 543.

Tocqueville, A. (2010). La democracia en América. Madrid: Trotta.

Tushnet, M. (1999). Taking the Constitution Away from the Courts. Princeton: Princeton University Press. 
- (2011). Abolishing Judicial Review. Constitutional Commentary, 27, 581.

- (2014). Advanced Introduction to Comparative Constitutional Law. Cheltenham: Edward Elgar.

Urosa Sánchez, J., San Miguel Pérez, E., Ruiz Rodríguez, I. y Marhuenda García, F. (1999). El Tribunal de Garantías constitucionales de la II República: colección documental. Madrid: Consejería de Educación de la Comunidad de Madrid.

Vanberg, G. (2001). Legislative-Judicial Relations: A Game-Theoretic approach to Constitutional Review. American Journal of Political Science, 45 (2), 346-361.

- (2015). Constitutional Courts in Comparative Perspective: A theoretical assessment. The Annual Review of Political Science, 18, 167-185.

Vega, P. de (1979). Jurisdicción constitucional y crisis de la constitución. Revista de Estudios Políticos, 7, 93-118.

Villaverde Menéndez, I. (2016). Cumplir o ejecutar: La ejecución de sentencias del Tribunal Constitucional y su reciente reforma. Teoría y Realidad Constitucional, 39, 643-682.

Viver Pi-Sunyer, C. (2013). Los efectos vinculantes de las sentencias del Tribunal Constitucional sobre el legislador: ¿puede éste reiterar preceptos legales que previamente han sido declarados inconstitucionales? Revista Española de Derecho Constitucional, 97, 13-44.

Wahl, R. y Wieland, J. (1997). La Jurisdicción constitucional como bien escaso: El acceso al Bundesverfassungsgericht. Revista Española de Derecho Constitucional, 51, 11-35.

Zagrebelsky, G. y Marcenò, V. (2012) Giustizia costituzionale. Bologna: Il Mulino. 